\title{
Methodical Tuning of Proportional Plus Integral Controllers for Cascade Control of Separately Excited DC Motors
}

\author{
Ibrahim Al-Abbas \\ Department of Mechatronics Engineering, \\ Faculty of Engineering Technology, Al-Balqa Applied University, Amman, Jordan
}

Received 2012-06-27, Revised 2012-09-07; Accepted 2012-09-12

\begin{abstract}
The cascade control of DC motors by PI controllers was extensively used in industry. Approximation rules based on plotting the output of the system or on computer simulation were used to determine the parameters of these controllers. This study was done to develop mathematical expressions to calculate the parameters of these controllers. Output time functions of the system and there derivatives were used to obtain mathematical relationships relating directly the motor parameters and the controller parameters. These relationships were used in tuning process of the cascade system. The dynamic performances of the system were examined in single loop form and in closed loop form for a step change in control variable (the input voltage) as well as for step change in disturbance (mechanical load). The performances of current closed loop system and the speed closed loop were acceptable. The steady state error was zero and the maximum overshoot was less than $20 \%$. The developed relationships can be used in design and analysis of cascade DC drive systems and cascade $\mathrm{AC}$ drive systems.
\end{abstract}

Keywords: Cascade Control, DC Motor, Ziegler Nichols, PI Control

\section{INTRODUCTION}

Cascade control of Separately Excited Direct Current (SEDC) motors can improve system performances over single-loop control, the control system has inner (current) loop and outer (speed) loop, where Proportional Plus Integral (PI) controller is implemented in each loop to provide fast response and zero steady state error. Different methods are used to select the gain and the time constant of PI controllers, these methods can be classified into three groups: The first one is Ziegler Nichols tuning rules used the plotted output time response curves (Sing and Pandey, 2012). Lee (2004) used the calculated gain margin and phase margin of the open loop system, it is known that gain and phase margins have served as important measures of robustness. The phase margin is related to the damping of the system from classical control theories and therefore also serves as a performance measurement. Their solutions are normally obtained numerically or graphically using bode plots. Moleykutty (2008) proposed a second method based on trial and error tuning of the controller from the simulated cascade
SEDC motor. The third method is the transfer function approach (Neenu and Poongodi, 2009) where the order of the open loop system is reduced to a second order with known parameters. To implement these methods some specifications should be measured to design the controller, therefore they can considered as indirect tuning methods.

In this study direct tuning methods for current controller and for speed controller are suggested, where the parameters of these controllers are calculated using obtained mathematical expressions without any plotting or simulations. For current (torque) loop using the time response output and its first and second derivatives mathematical expressions was obtained to determine the proportional gain and the time constant of PI controller from the parameters of the DC motor. For speed loop the characteristic equation of the close loop system is used to relate the motor parameters and controller parameters. The cascade system is simulated using calculated parameters of current controller and speed controller and the time response of both loops are investigated for varying input and step change in load torque. 


\section{MATERIALS AND METHODS}

\subsection{Reaction Curve Parameters}

The open loop step response reaction (S-shape) curve $y(t)$ of a control system is shown on Fig. 1. This curve has an inflection point at time $t_{\text {inf, }}$ where the first derivative reaches its maximum value and the second derivative is zero.

Traditional tuning method used measuring to determine the parameters of this response: L-the delay time and T-the time constant by plotting tangent at inflection point as shown on Fig. 2.

To determine the delay time and the time constant of response analytically we follow the following steps:

Step1: From the known time function $y(t)$, determine the first derivative $y^{\prime}(t)$ and the second derivative $\mathrm{y}^{\prime \prime}(\mathrm{t})$

Step2: Equating the second derivative to zero and solving this equation obtain $t_{\text {inf }}$, the time where the reaction curves exhibit inflection
Step3: Substituting the value of the inflection time into the expression of the first derivative, determine the maximum value $y^{\prime}(t)_{\max }$, which is the tangent of angle a

Step4: Using the triangular $(\mathrm{b} 1, \mathrm{~b} 2, \mathrm{~b} 3)$ on Fig. 2, determine tan a

$\tan \alpha=\frac{\mathrm{y}\left(\mathrm{t}_{\text {inf }}\right)}{\mathrm{t}_{\text {inf }}-\mathrm{L}}$ Or: $\mathrm{L}=\mathrm{t}_{\text {inf }}-\frac{\mathrm{y}\left(\mathrm{t}_{\text {inf }}\right)}{\tan \alpha}$

Step 5: Using the triangular(b1,b4,b5) on Fig. 2 find T:

$\tan \alpha=\frac{\mathrm{y}_{\mathrm{ss}}}{\mathrm{T}}$, or $\mathrm{T}=\frac{\mathrm{y}_{\mathrm{ss}}}{\tan \alpha}$

where the steady state value of the output $\mathrm{y}_{\mathrm{ss}}$ :

$\mathrm{y}_{\mathrm{ss}}=\operatorname{Limy}(\mathrm{t})$

Step6: Use the calculated reaction curve parameters $\mathrm{L}$ and $\mathrm{T}$ and Ziegler-Nichols rules to tune the PI controller.

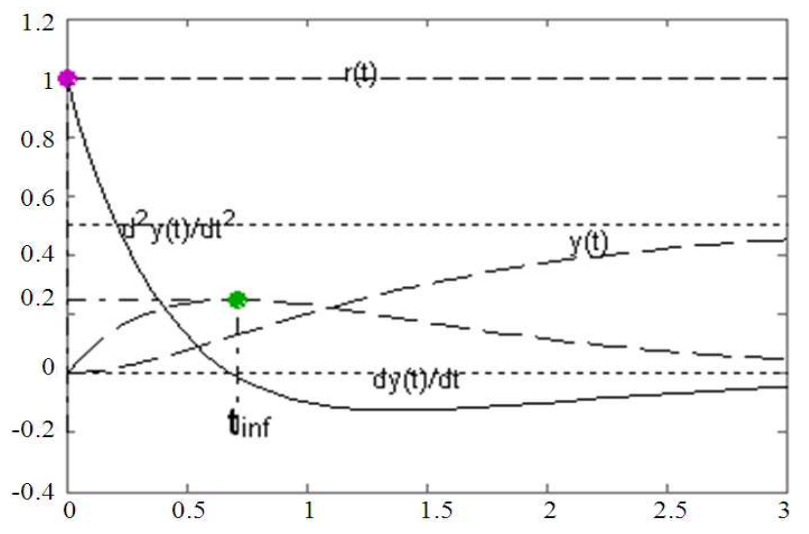

Fig. 1. Reaction curve y $(\mathrm{t})$ and its derivatives

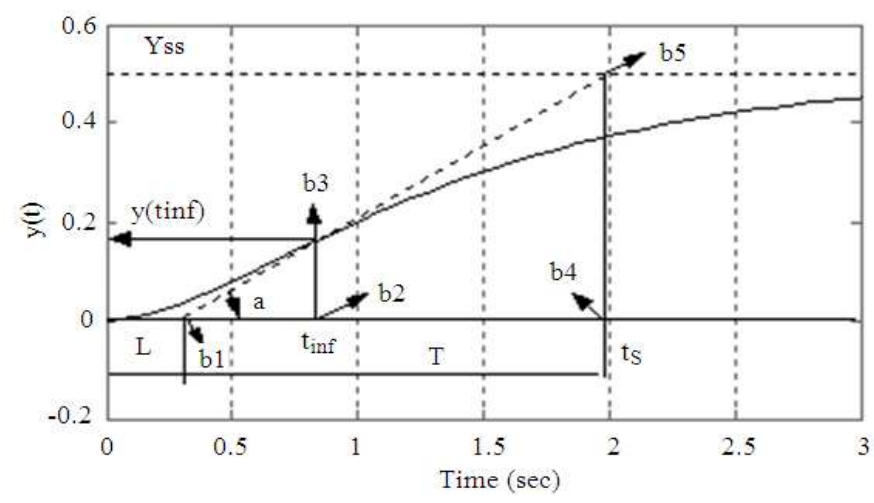

Fig. 2. The parameters of reaction curve 


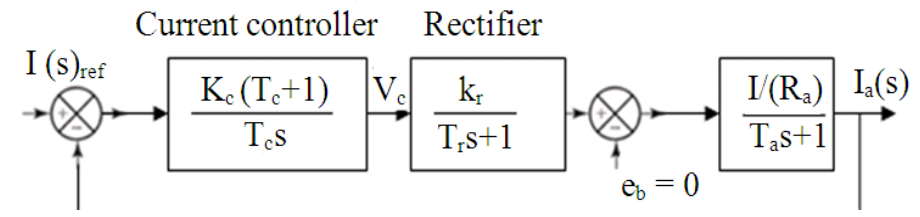

Fig. 3. Closed loop armature current block diagram

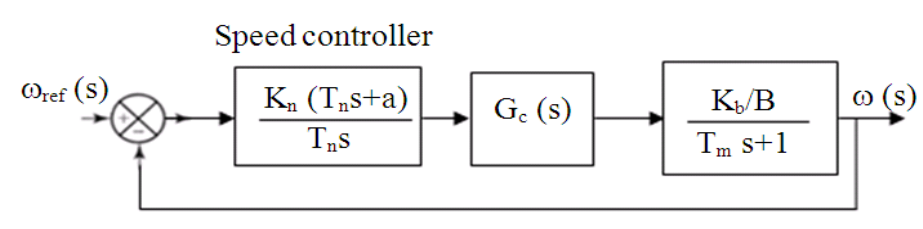

Fig. 4. Closed loop speed control system block diagram

Equations (1-3) show how the output and its derevatives can be used to obtain reaction curve parameters.

\subsection{Armature Current PI Controller Design}

The current controller is designed for the extreme condition when back emf is zero, that is during starting period because at that time large current flows through the machine. The block diagram of the clopsed loop armature current is depicted on Fig. 3 where: $R_{a}$ the armature resistance, $L_{a}$ the armature inductance, $K_{r}$ rectifier gain, $T_{r}$ rectifier time constant, $K_{c}$ PI controller gain and $\mathrm{T}_{\mathrm{c}}$ PI controller time constant.

The plant transfer function is Equation 4:

$G_{p}(s)=\frac{I_{a}(s)}{V_{c}(s)}=\frac{K_{r} / R_{a}}{\left(T_{a} s+1\right)\left(T_{r} s+1\right)}$

Assume a step change in $\mathrm{V}_{\mathrm{c}}$ and taking inverse Laplace transform of both sides, we obtain the armature current and its derivatives:

$$
\begin{aligned}
& i_{a}(t)=\frac{V_{c} K_{r}}{R_{a}}\left(1-\frac{T_{a}}{T_{a}-T_{r}} e^{-t / T_{a}}\right. \\
& \left.-\frac{T_{r}}{T_{r}-T_{a}} e^{-t / T_{r}}\right) \\
& i_{a}^{\prime}(t)=\frac{V_{c} K_{r}}{R_{a}\left(T_{a}-T_{r}\right)}\left(e^{-t / T_{a}}-e^{-t / T_{r}}\right) \\
& i_{a}^{\prime \prime}(t)=\frac{V_{c} K_{r}}{R_{a}\left(T_{a}-T_{r}\right)}\left(-\frac{1}{T_{a}} e^{-t / T_{a}}+\frac{1}{T_{r}} e^{-t / T_{r}}\right)
\end{aligned}
$$

Equation (5) indicates that the armature current has two exponential terms and a constant term, that is mean the output is of S-shape. The first derevative given by Equation (6) has a maximum value and its derevative represented by Equation (7) has an intersection point with real axis.These specifications will be used to determine reaction curve parameters.

Equating the second derivative given by Equation (7) to zero and solving for inflection time results:

$$
t_{\text {inf }}=\frac{T_{a} T_{r}}{T_{a}-T_{r}} \ln \frac{T_{a}}{T_{r}}
$$

Without ploting the output of the loop $i(t)$.using Equations (8) and (7) the angle of the tangent to the reaction curve can be calculated, then using Equations (1) and (2) the parameters of the response are obtained and implemented in tuning the PI controller and for better response modified Ziegler-Nichols rules are used in this study.

\subsection{Speed PI Controller Design}

The block diagram of the closed loop speed control system is presented on Fig. 4 where $K_{b}$ is the torque constant, $B$ is the viscous friction coefficient, $T_{m}$ is the mechanical time constant, $K_{n}$ and $T_{n}$ are the speed PI controller gain and time constant respectively, $\mathrm{G}_{\mathrm{c}}(\mathrm{s})$ is the armature current closed loop transfer function. $\mathrm{T}_{\mathrm{n}}$ should be chosen such that it cancels the largest time constant in the transfer function in order to reduce the order of the system. Therefore the response will be much faster. The speed open loop transfer function is Equation (9):

$\frac{\mathrm{K}_{\mathrm{n}} \mathrm{b}_{0} \mathrm{~s}+\mathrm{b}_{1} \mathrm{~K}_{\mathrm{n}}}{\mathrm{a}_{0} \mathrm{~s}^{4}+\mathrm{a}_{1} \mathrm{~s}^{3}+\mathrm{a}_{2} \mathrm{~s}^{2}+\mathrm{a}_{3} \mathrm{~s}}$

where the coefficients of the transfer function are: 


$$
\begin{aligned}
& \mathrm{b}_{0}=\mathrm{K}_{\mathrm{c}} \mathrm{K}_{\mathrm{r}} \mathrm{K}_{\mathrm{B}} \mathrm{T}_{\mathrm{c}} \\
& \mathrm{b}_{\mathrm{1}}=\mathrm{K}_{\mathrm{c}} \mathrm{K}_{\mathrm{r}} \mathrm{K}_{\mathrm{B}} \\
& \mathrm{a}_{0}=\mathrm{T}_{\mathrm{c}} \mathrm{T}_{\mathrm{r}} \mathrm{T}_{\mathrm{m}} \mathrm{L}_{\mathrm{a}} \\
& \mathrm{a}_{1}=\mathrm{T}_{\mathrm{c}} \mathrm{Tm}\left(\mathrm{L}_{\mathrm{a}}+\mathrm{T}_{\mathrm{r}}\right)+\mathrm{T}_{\mathrm{c}} \mathrm{T}_{\mathrm{r}} \mathrm{L}_{\mathrm{a}} \\
& \mathrm{a}_{2}=\mathrm{T}_{\mathrm{m}}\left(\mathrm{T}_{\mathrm{c}} \mathrm{R}_{\mathrm{a}}+\mathrm{K}_{\mathrm{r}} \mathrm{K}_{\mathrm{c}} \mathrm{L}_{\mathrm{a}}\right)+\mathrm{T}_{\mathrm{c}}\left(\mathrm{T}_{\mathrm{r}}+\mathrm{L}_{\mathrm{a}}\right) \\
& \mathrm{a}_{3}=\mathrm{T}_{\mathrm{m}} \mathrm{K}_{\mathrm{r}} \mathrm{K}_{\mathrm{c}} \mathrm{R}_{\mathrm{a}}+\mathrm{T}_{\mathrm{c}} \mathrm{R}_{\mathrm{a}}+\mathrm{K}_{\mathrm{r}} \mathrm{K}_{\mathrm{c}} \mathrm{L}_{\mathrm{a}} \\
& \mathrm{a}_{4}=\mathrm{K}_{\mathrm{r}} \mathrm{K}_{\mathrm{c}} \mathrm{R}_{\mathrm{aa}}
\end{aligned}
$$

Equations (10-16) give the relatinoships between the system parameters and the coefficients of the trsnsfer functin of the same system and will be used in determing the critical gain and the critecal period nessecary to tuned the speed PI controller.

The speed open loop system has a zero on the origin and the time response exhibits sustained oscillations when the proportional gain is at critical value $\mathrm{K}_{\mathrm{cr}}$, this critical value can be obtain theoretically from the Routh's stability criterion using the following speed closed loop transfer function:

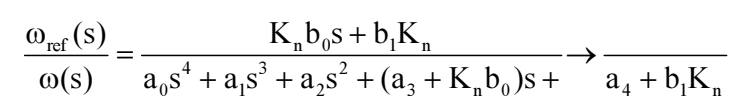

The characteristic Equation (17) of the speed closed loop system is:

$$
a_{0} s^{4}+a_{1} s^{3}+a_{2} s^{2}+\left(a_{3}+K_{n} b_{0}\right) s+a_{4}+b_{1} K_{n}=0
$$

From Equation (18)arrange Routh's array as shown on Table 1,where:

$$
\begin{aligned}
& A=\frac{\left(a_{1} a_{2}-a_{0} a_{3}-a_{0} b_{0} K_{n}\right)}{a_{1} a_{2}-a_{0}\left(a_{3}+K_{n} b_{0}\right)} \rightarrow \\
& \rightarrow \underline{\left(a_{3}+K_{n} b_{0}\right)-a_{1}^{2} b_{1} K_{n}+a_{4}}
\end{aligned}
$$

Examining the array of coefficients, the speed closed loop system becomes oscillatory when A equals zero, i.e:

$$
\begin{aligned}
& \left(a_{1} a_{2}-a_{0} a_{3}-a_{0} b_{0} K_{c r}\right)\left(a_{3}+b_{0} K_{c r}\right)+ \\
& -a_{1}^{2}\left(b_{1} K_{c r}+a_{4}\right)=0
\end{aligned}
$$

Table 1. The array of coefficients

\begin{tabular}{ll}
\hline$S^{4} a_{0}$ & $a_{2} a_{4}+b_{1} K_{n}$ \\
\hline$S^{3} a_{1}$ & $a_{3}+K_{n} b_{0} 0$ \\
$S^{2} \frac{a_{1} a_{2}-a_{0}\left(a_{3}+K_{n} b_{0}\right)}{a_{1}}$ & $a_{4}+b_{1} K_{n}$ \\
$S A$ & 0 \\
$S^{0} a_{4}+b_{1} K_{n}$ & 0 \\
\hline
\end{tabular}

Solving Equation 19, for critical gain results:

$\mathrm{K}_{\mathrm{cr}}=-\mathrm{K}_{1} \pm \sqrt{\left(\mathrm{K}_{1}^{2}-\mathrm{K}_{2}\right)}$

Where:

$$
\begin{aligned}
& \mathrm{K}_{1}=\frac{\mathrm{b}_{0}\left(2 \mathrm{a}_{0} \mathrm{a}_{3}-\mathrm{a}_{1} \mathrm{a}_{2}+\mathrm{a}_{1}^{2} \mathrm{~b}_{1}\right.}{2 \mathrm{a}_{0} \mathrm{~b}_{0}^{2}} \\
& \mathrm{~K}_{2}=\frac{\mathrm{a}_{3}\left(\mathrm{a}_{0} \mathrm{a}_{3}-\mathrm{a}_{1} \mathrm{a}_{2}\right)+\mathrm{a}_{1}^{2} \mathrm{a}_{4}}{2 \mathrm{a}_{0} \mathrm{~b}_{0}^{2}}
\end{aligned}
$$

The proportional gain of speed PI controller is determined using the calculated critical gain, equations (18-23) and the modified second Ziegler Nichols method for low overshoot of the output signal.

To find the frequency of the sustained oscillations a supplementary equation is performed using the coefficients of the third raw in Routh's table as:

$$
\frac{\mathrm{a}_{1} \mathrm{a}_{2}-\mathrm{a}_{0}\left(\mathrm{a}_{3}+\mathrm{K}_{\mathrm{cr}} \mathrm{b}_{0}\right)}{\mathrm{a}_{1}} \mathrm{~s}^{2}+\mathrm{a}_{4}+\mathrm{b}_{1} \mathrm{~K}_{\mathrm{cr}}=0
$$

Replacing s by j $\omega$ and solving Equation (24):

$$
\omega_{c r}= \pm j \sqrt{\frac{a_{1}\left(b_{1} K_{c r}+a_{4}\right)}{\left(a_{1} a_{2}-a_{0} a_{3}-a_{0} K_{c r} b_{0}\right)}}
$$

The period of sustained oscillation is:

$\mathrm{P}_{\mathrm{cr}}=2 \pi / \omega_{\mathrm{cr}}$

Equations (24-26) determened the critical period of the speed closed loop system, then the parameters of the PI speed controller can be adjusted from the calculated critical gain and critical period.

\subsection{Cascade System Simulation}

A double loop cascade control system is simulated using the following components.

1: 5 HP, 240V separately excited DC motor with parameters as:

Moment of Inertia, $\mathrm{J}=0.05 \mathrm{Kg} . \mathrm{m}^{2}$. 


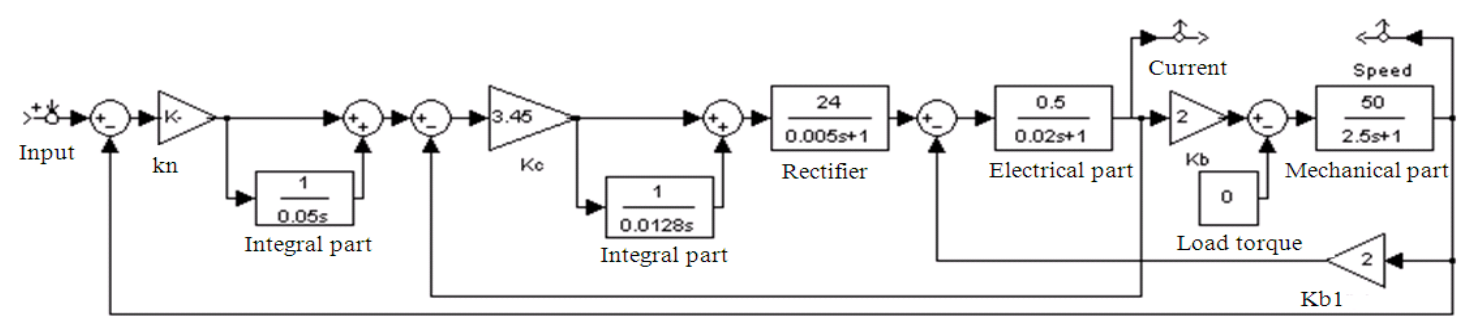

Fig. 5. MATLAB/Simulink model of cascade system

Back EMF Constant $\mathrm{Ke}=2$ Volt.sec/rad.

Rated Current $=16 \mathrm{~A}$.

Resistance of Armature, $\mathrm{R}_{\mathrm{a}}=0.5 \mathrm{ohm}$.

Armature Inductance, $\mathrm{L}_{\mathrm{a}}=0.01 \mathrm{H}$.

Viscous friction coefficient, $\mathrm{B}=0.02 \mathrm{Nm} / \mathrm{rad} / \mathrm{s}$

Mechanical time constant $T_{\mathrm{m}}=\mathrm{J} / \mathrm{B} \mathrm{s}$

Torque constant $\mathrm{KB}=\mathrm{K}_{\mathrm{e}} / \mathrm{B}$

2: Single phase rectifier:

Rectifier gain, $\mathrm{K}_{\mathrm{r}}=24$

Rectifier time constant, $\mathrm{T}_{\mathrm{r}}=0.005 \mathrm{~s}$

Input control signal, $\mathrm{V}_{\mathrm{c}}=10 \mathrm{~V}$

3: PI current controller:

Proportional gain, $\mathrm{K}_{\mathrm{c}}=3.45$

Integral time constant, $\mathrm{T}_{\mathrm{c}}=0.0128 \mathrm{~s}$

4: PI speed controller:

Proportional gain, $\mathrm{K}_{\mathrm{n}}=0.96$

Integral time constant, $\mathrm{T}_{\mathrm{n}}=0.05 \mathrm{~s}$

The components of the cascade system connected together are shown on Fig. 5 where the current loop contains the armature circuit (electrical part), the rectifier and PI current controller and the speed loop contains the closed loop current loop, mechanical part and PI speed controller.

\section{RESULTS}

In order to validate the control strategies were developed, simulations are carried out. These simulations are made for current control loop and for speed control loop.

\subsection{Armature Current Closed Loop Response}

The dynamic performances of the closed loop armature current are obtained using MATLAB/Simulink model of cascade system shown on Fig. 5 when the PI speed controller is disconnected and the reference signal is applied directly to the PI current controller.

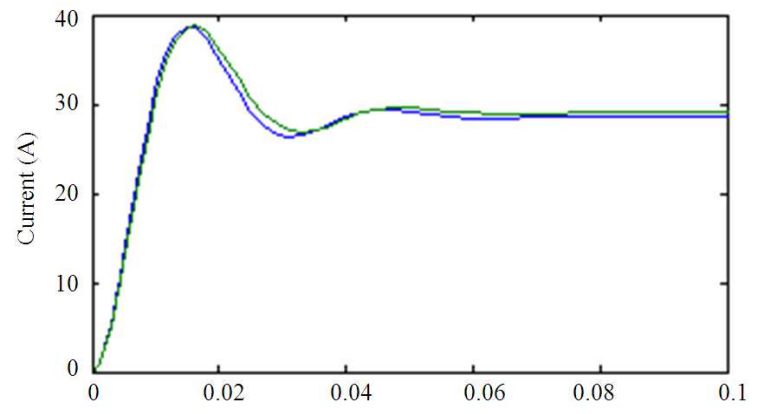

Fig. 6. Current loop start up time response

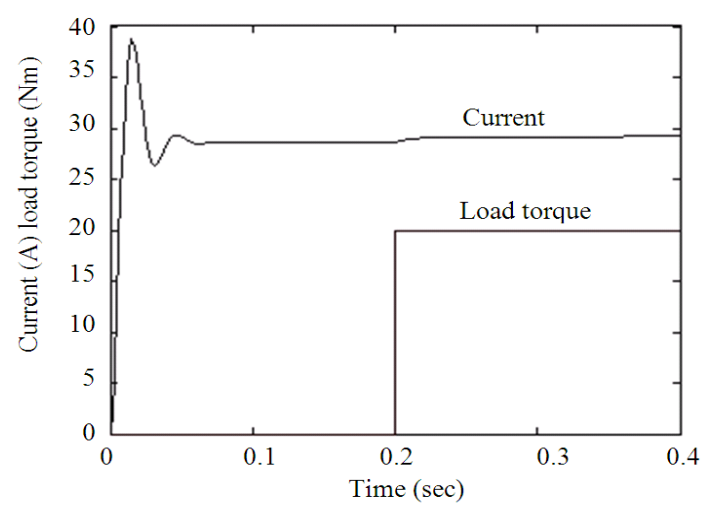

Fig. 7. Current loop time response to step change on load torque

The startup time response of the closed loop armature current is shown on Fig. 6. The figure shows two curves, one curve for no load star up and the other when the motor starts with half rated load on the shaft, the plot indicates that both curves are approximately identical, which means the current closed loop rejects the disturbances caused by the mechanical load. From other hand the maximum overshoot is nearly $30 \%$. This value of overshoot is acceptable, because the rated starting current of DC motors is twice the name plate current. The time response is 10 time faster than the response of uncontrolled system. 
The time response of the closed loop armature current to a $50 \%$ step change on load torque is plotted on Fig. 7. The step change in load torque is applied at $t=0.2$ sec before this time the motor was running on steady state operating point. The oscillations of armature current is smaller than the oscillations cause by the reference signal.

\subsection{Angular Speed Closed Loop Response}

The start up time response of the speed closed loop system is shown on Fig. 8 with no load and with rated load. These two curves indicate that disturbance in cascade system has no effect on the dynamic performances.

On Fig. 9 the time response of the speed loop for step change on motor load applied at $\mathrm{t}=0.5 \mathrm{sec}$ is plotted. The speed of cascade system oscillates in the region of its steady state value and then go back to the speed determine by reference signal, this means that the steady state error of this closed loop is zero.

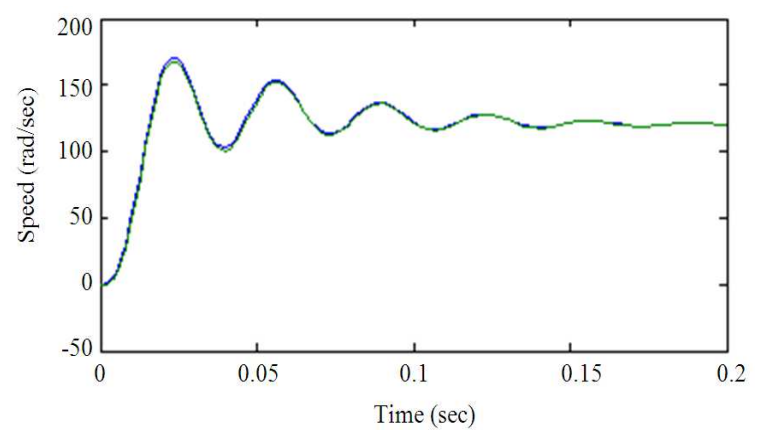

Fig. 8. Speed loop start up time response

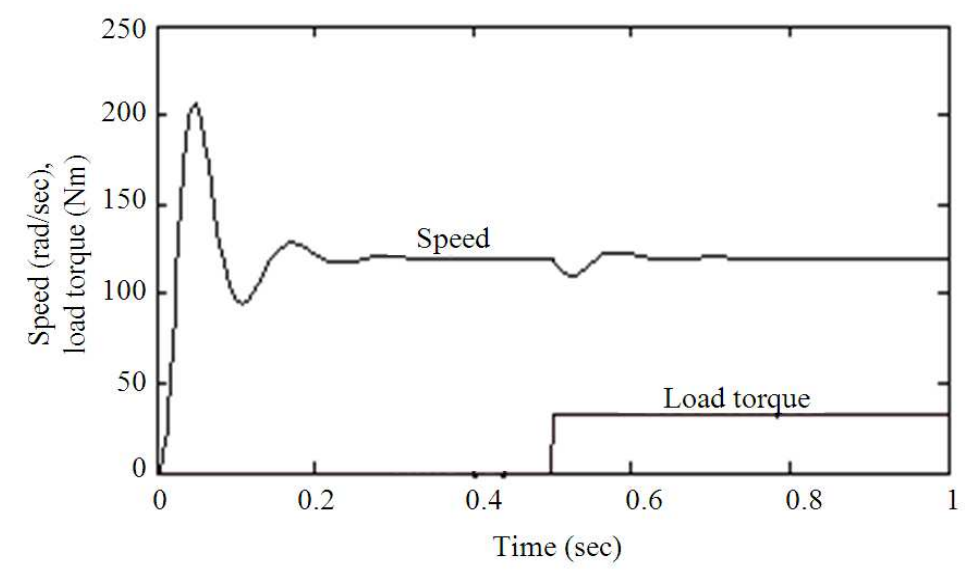

Fig. 9. Speed loop time response to step change on load torque

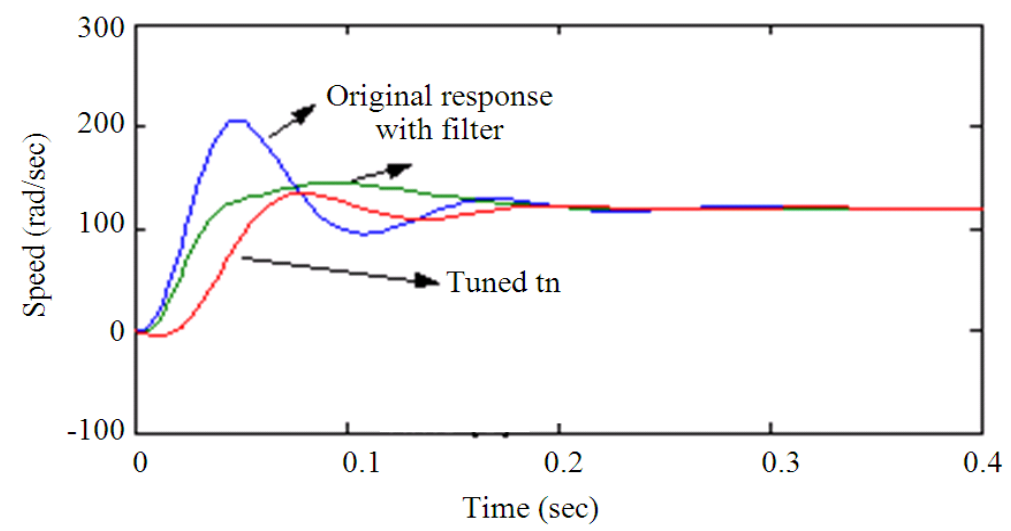

Fig. 10. Tuning the time response of speed loop 


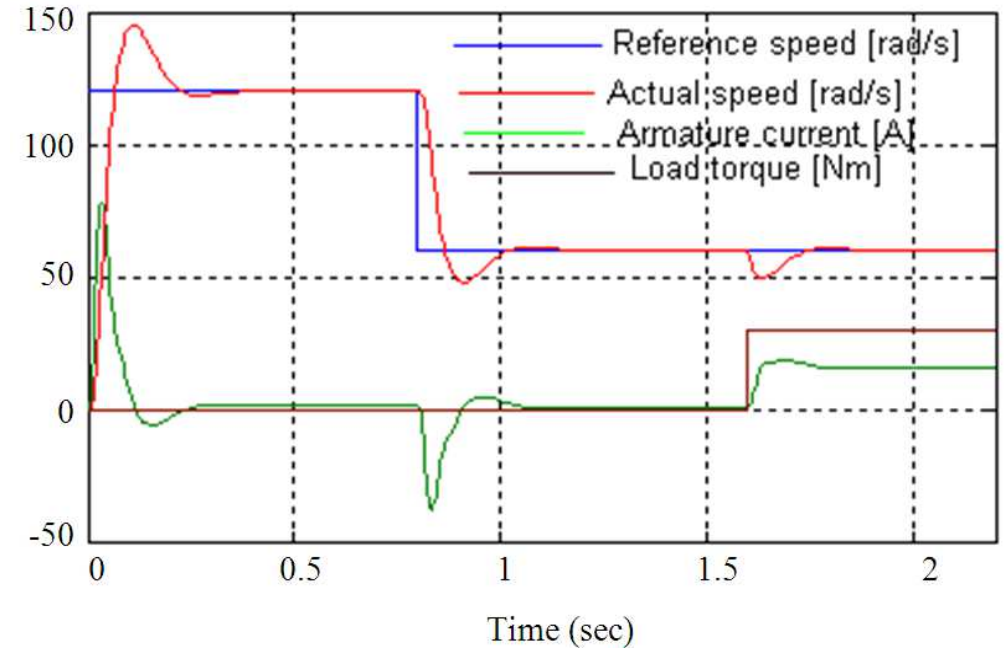

Fig. 11. Time response of the hall system

To achieve preferred overshoot for the speed loop, Crnosija et al. (2005) inserted a filter with unity gain and different value of time constant on the system input. If the time constant of the input filter is $0.02 \mathrm{sec}$, the percent maximum overshoot is reduced from 70 to $10 \%$ as exposed on Fig. 10.

The maximum overshoot can be reduced by tuning the parameters of PI speed controller especially the integration time constant $T_{n}$, but the speed of the system response is lower. Finally, the time response of the drive system is presented on Fig. 11. When the reference signal is reduced by $50 \%$ at $\mathrm{t}=0.8 \mathrm{sec}$ and the load torque is increased to its nominal value at $\mathrm{t}=1.6 \mathrm{sec}$.

\section{DISCUSSION}

This study covers an analytical method for design of double loop cascade system contains a separately excite DC motor and full controlled single phase rectifier. For inner loop (armature current loop), using the armature current time function and its derivates a mathematical expressions are derived for reaction curve parameters, they are the delay time (l) and the Time constant (T), these two parameters are used to calculate the gain and time constant of a proportional plus integral controller, the calculated parameters are implemented in simulations investigation the time response performances of this loop.

For the outer loop (speed loop), critical gain and the critical period of the oscillated response are determined using developed relation ships and implemented to determine the speed PI controller parameters. The dynamic behavior of the speed closed loop is analyzed using Simulink software. Different tuning rules for both controllers were examined during simulations.

The time response of the armature current closed loop is fast, has zero steady state error and acceptable overshoot for DC motors. The time response of the speed closed loop has one disadvantage which that a high percent overshoot but its corrected using a filter in the input of the system

\section{CONCLUSION}

In the present study, a mathematical expression for armature current PI controller and for speed of rotation PI controller are derived and used in calculations of the gain and of the time constant for both controllers. The cascade system is simulated and the time response is plotted and investigated. For current loop it is better to adjust the parameters of PI controller applying modified Ziegler-Nichols first method to reduce the overshoot of the armature current, while for speed PI controller it is reasonable to implement modified second ZieglerNichols method for small overshoot and tune the integrator time constant, or better introduce a filter into the input of the system.

The proposed method for determination of the parameters of the controllers can be used in all DC drive systems and in AC drive systems, also in process control system with a single closed loop where PI controller is replaced by PID controller. 


\section{REFERENCES}

Crnosija, P., R. Krishnan and T. Bjazic, 2005. Transient performance based design optimization of PM brushless DC motor drive speed controller. Proceedings of the IEEE International Symposium on Industrial Electronics, Jun. 20-23, IEEE Xplore Press, $\quad$ pp: $881-886$. DOI: 10.1109/ISIE.2005.1529040

Lee, C.H., 2004. A survey of PID controller design based on gain and phase margin. Int. J. Comput. Cognit., 2: 63-100.

Moleykutty, G., 2008. Speed control of separately excited DC motor. Am. J. Applied Sci., 5: 227-233. DOI: 10.3844/ajassp.2008.227.233
Neenu, T. and P. Poongodi, 2009. Position control of DC motor using genetic algorithm based PID controller. Proceedings of the World Congress on Engineering, Jul. 1-3, London, UK., pp: 1618-1622.

Sing, R. and A.K. Pandey, 2012. Stability analysis of closed loop control of SEDC motor using routhhurwitz criteria. GJCAT, 2: 926-928. 